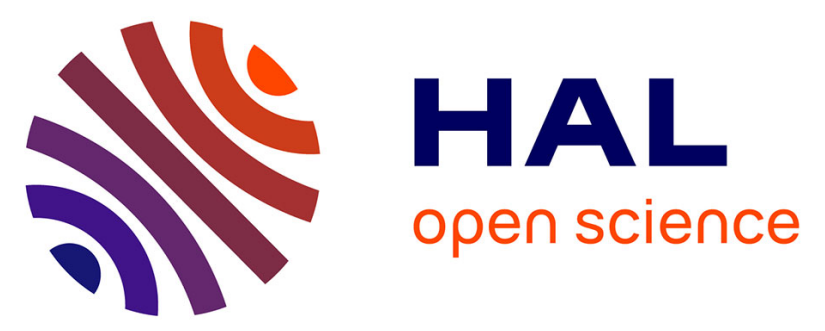

\title{
Pharmacist intervention to detect drug adverse events on admission to the emergency department: Two case reports of neuroleptic malignant syndrome
}

F. Leenhardt, D. Perier, V. Pinzani, I. Giraud, M. Villiet, A. Castet-Nicolas, V. Gourhant, Cyril Breuker

\section{To cite this version:}

F. Leenhardt, D. Perier, V. Pinzani, I. Giraud, M. Villiet, et al.. Pharmacist intervention to detect drug adverse events on admission to the emergency department: Two case reports of neuroleptic malignant syndrome. Journal of Clinical Pharmacy and Therapeutics, 2017, 42 (4), pp.502 - 505. 10.1111/jcpt.12531 . hal-01833577

\section{HAL Id: hal-01833577 \\ https://hal.umontpellier.fr/hal-01833577}

Submitted on 17 Dec 2019

HAL is a multi-disciplinary open access archive for the deposit and dissemination of scientific research documents, whether they are published or not. The documents may come from teaching and research institutions in France or abroad, or from public or private research centers.
L'archive ouverte pluridisciplinaire HAL, est destinée au dépôt et à la diffusion de documents scientifiques de niveau recherche, publiés ou non, émanant des établissements d'enseignement et de recherche français ou étrangers, des laboratoires publics ou privés. 


\title{
Pharmacist intervention to detect drug adverse events on admission to the emergency department: Two case reports of neuroleptic malignant syndrome
}

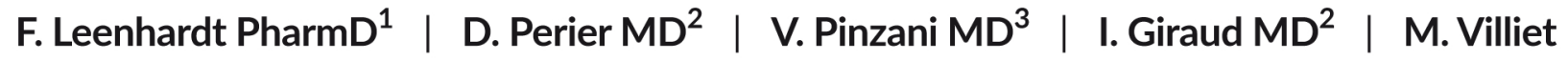 \\ PharmD ${ }^{1}$ | A. Castet-Nicolas PharmD, PhD ${ }^{1}$ | V. Gourhant MD $^{2}$ | C. Breuker PharmD, PhD ${ }^{1,4}$
}

${ }^{1}$ Clinical Pharmacy Department, University Hospital, Montpellier, France

${ }^{2}$ Emergency Department, University Hospital, Montpellier, France

${ }^{3}$ Medical Pharmacology and Toxicology Department, University Hospital, Montpellier, France

${ }^{4}$ PhyMedExp, INSERM U1046, CNRS UMR 9214, University of Montpellier, France

\section{Correspondence}

C. Breuker, Clinical Pharmacy Department, University Hospital, Montpellier, France.

Email: c-breuker@chu-montpellier.fr

\begin{abstract}
Summary
What is known and objective: Neuroleptic malignant syndrome (NMS) is a rare but severe adverse effect of antipsychotic drugs.

Case description: We report two cases of NMS highlighted by clinical pharmacists in an emergency unit during summer. One of them was fatal. Medication reconciliation processes performed at admission identified treatment with loxapine for one of them and with loxapine and clozapine for the other. Interview of the patients highlighted clinical symptoms suggesting NMS, allowing the pharmacists to alert the medical team. What is new and conclusion: Adverse drug events may be severe and clinical pharmacists in emergency departments can help to detect them.
\end{abstract}

\section{KEYWORDS}

accident and emergency departments, adverse effect, clinical pharmacy, clozapine, loxapine, pharmacist consultation

\section{1 | WHAT IS KNOWN AND OBJECTIVE}

Neuroleptic malignant syndrome (NMS) is a rare but severe adverse effect of antipsychotic drugs. NMS is characterized by hyperthermia and muscle rigidity, and at least two of the following symptoms: change in mental status, hypertension, tachycardia, shaking, incontinence, or creatine kinase (CK) increase and/or leukocytosis. ${ }^{1}$ Furthermore during heatwave, neuroleptics (NL) may affect the body's thermoregulation. $^{2}$ Despite a large use of antipsychotics, this syndrome is rarely notified to health authorities. At the university hospital of Montpellier in France, a pharmaceutical team is present in the Emergency Department (ED) to detect hospital admissions caused by iatrogenic events. After triage and before or during medical examination, the clinical pharmacist questions patients about their clinical history, current treatments and reason for ED presentation, looking for evidence of an iatrogenic event. latrogenic events are identified by clinical pharmacists on the basis of collected data using their clinical knowledge and validated databases, such as VIDAL dictionary (French book summarizing the characteristics of all medications, including pharmacology, adverse effects and drug-drug interactions). In case of doubt about an iatrogenic event, the cases are reviewed by an expert committee including emergency physicians, clinical pharmacists and pharmacovigilance physicians.

During July 2015, two patients admitted to the ED of our hospital, presented with NMS in the course of heatwave. We describe these two cases and the role of the clinical pharmacists in their detection.

\section{2 | CASE DESCRIPTION}

Patient $A$ was a 49-year-old man with a body mass index (BMI) of $31.1 \mathrm{~kg} / \mathrm{m}^{2}$ and a history of mental disorders (persecution delusions), depression and diabetes. The patient was admitted to the ED in July 2015. He presented a fever over $39.5^{\circ} \mathrm{C} / 103.1^{\circ} \mathrm{F}$ for 7 days. At the ED, clinical examination showed a high blood pressure $(163 / 90 \mathrm{~mm}$ $\mathrm{Hg}$ ), increases in heart rate (139 bpm), a fever around $40.8^{\circ} \mathrm{C} / 105.4^{\circ} \mathrm{F}$ with extrapyramidal reactions, confusion, cogwheel movement and muscle rigidity without infection signs. Cerebral scanner and lumbar 


\begin{tabular}{|c|c|c|c|}
\hline & Patient A & Patient B & Normal values \\
\hline Blood pressure (mm Hg) & $163 / 90$ & $190 / 92$ & $120 / 80$ \\
\hline Heart rate (beats per minute) & 139 & 153 & $60-100$ \\
\hline $\begin{array}{l}\text { Respiratory rate (respiratory } \\
\text { cycle per minute) }\end{array}$ & 18 & 44 & $12-18$ \\
\hline Physical temperature $\left({ }^{\circ} \mathrm{C} /{ }^{\circ} \mathrm{F}\right)$ & $40.8 / 105.4$ & $41.2 / 106.2$ & $37.0 / 98.6$ \\
\hline \multirow[t]{2}{*}{ Oxygen saturation $\left(\% \mathrm{O}_{2}\right)$} & 93 & 99 & $95-100$ \\
\hline & Patient A & Patient B & Normal values \\
\hline Leucocytes (g/L) & 6200 & 12800 & $4000-10000$ \\
\hline Enzymatic creatinine $(\mu \mathrm{mol} / \mathrm{L})$ & 84 & 132 & $60-110$ (for men) \\
\hline Sodium concentration (mmol/L) & 120 & 131 & $135-145$ \\
\hline $\begin{array}{l}\text { Potassium concentration } \\
(\mathrm{mmol} / \mathrm{L})\end{array}$ & 3.8 & 4.3 & $3.5-5.0$ \\
\hline Creatine kinase (UI/L) & 419 & 562 & $<190$ \\
\hline Myoglobin $(\mu \mathrm{g} / \mathrm{L})$ & 164.8 & 275.5 & $28-72$ \\
\hline Lactic acid (mmol/L) & 1.2 & 4.4 & $0.5-2$ \\
\hline C-reactive protein $(\mathrm{mg} / \mathrm{L})$ & 0.9 & 2.5 & $<6$ \\
\hline Procalcitonin (ng/mL) & Not informed & 0.16 & $<0.10$ \\
\hline
\end{tabular}

TABLE 1 Vital parameters at the time of emergency room admission for patients $A$ and $B$

TABLE 2 Biological parameters at the time of emergency room admission for patients $\mathrm{A}$ and $\mathrm{B}$ puncture were normal. His vital and biological parameters at emergency admission are described in Tables 1 and 2. At admission, a medication reconciliation process was performed by the clinical pharmacist. The patient's treatment included sodium valproate (dose unknown), clozapine $100 \mathrm{mg} / \mathrm{d}$, tropatepine hydrochloride $10 \mathrm{mg} / \mathrm{d}$, loxapine $100 \mathrm{mg} / \mathrm{d}$, duloxetine $60 \mathrm{mg} / \mathrm{d}$, piribedil $50 \mathrm{mg} / \mathrm{d}$ and metformin $3000 \mathrm{mg} / \mathrm{d}$. After the patient's consultation, the clinical pharmacist advised the medical team of the possibility of a NMS. The patient's NL treatment was stopped and, due to the absence of severity criterion, there was no indication to initiate muscle relaxant treatment. The symptoms resolved within the following few days, and he was discharged on day 11.

Patient B was a 71-year-old man with a history of schizophrenia (acute mania and symptoms of psychosis), chronic liver failure, vascular dementia and morbid obesity with BMI of $47 \mathrm{~kg}$ / $\mathrm{m}^{2}$. In July 2015, he was admitted to the hospital for confusion with hyperthermia $\left(41.2^{\circ} \mathrm{C} / 106.2^{\circ} \mathrm{F}\right)$, recent muscle rigidity and clinical signs of dehydration (Table 1). Elevated levels of leukocytosis (12800 g/L) and CK (562 UI/L) were found at admission (Table 2) and increased rapidly in the first 12 hours (CK $1989 \mathrm{UI} / \mathrm{L}$ and leucocyte $22600 \mathrm{~g} / \mathrm{L}$ ) and 24 hours (CK $6760 \mathrm{UI} / \mathrm{L}$, leucocyte $18600 \mathrm{~g} / \mathrm{L}$ and CRP $12.6 \mathrm{mg} / \mathrm{L}$ ) of hospitalization. The best possible medication history performed by the clinical pharmacist revealed chronic treatment with furosemide $20 \mathrm{mg} / \mathrm{d}$ and loxapine $100 \mathrm{mg} / \mathrm{d}$ for the past 5 years, suggesting the possibility of NMS after discussion between medical and pharmaceutical teams. Despite antibiotic treatment (ceftriaxone and levofloxacin) for managing a possible lung infection, subsequently not confirmed, the patient's status rapidly worsened with poor conscious state (Glasgow score of 6). He needed artificial ventilation and vasopressive drugs (noradrenaline) for hypotension $(80 / 50 \mathrm{~mm} \mathrm{Hg}$ ) and haemodynamic instability. He was quickly transferred to the intensive care unit before muscle relaxant treatment could be initiated. Then, he developed multiple organ failure with secondary acute renal insufficiency requiring dialysis, metabolic acidosis (blood parameters: $\mathrm{pH}=7.28$; pCO2 $=41 \mathrm{~mm} \quad \mathrm{Hg} ; \quad \mathrm{pO} 2=84 \mathrm{~mm} \mathrm{Hg}$; bicarbonates $=17 \mathrm{mmol} / \mathrm{L}$; lactate $=5.1 \mathrm{mmol} / \mathrm{L}$ ), rhabdomyolysis (blood parameters: myoglobin=6760 UI/L; CK=2336 UI/L), nosocomial pneumonia (Klebsiella pneumonia) and cardiopulmonary arrest in connection with severe hypoxia requiring cardiopulmonary resuscitation. Cerebral damage was found (flat line on electroencephalogram and extensive bilateral cortical necrotic lesions on brain MRI). The patient died 22 days after the onset of symptoms.

Both cases were reviewed by the expert committee and were reported to the regional pharmacovigilance centre.

\section{WHAT IS NEW AND CONCLUSION}

NMS is described by the American Psychiatric Association's Diagnostic and Statistical Manual of Mental Disorders, Fourth Edition as occurrence of muscle rigidity and elevated temperature during treatment with a NL medication, and the presence of at least two other symptoms among tachycardia, hypotension or hypertension, change in mental status with alteration in consciousness, profuse sweats, incontinence, CK increase and leukocytosis. ${ }^{3}$ Usually, NMS occurs in the first 4 weeks after neuroleptic treatment onset. In two-thirds of the cases, it appears during the first week of treatment. ${ }^{4}$ However, NMS can occur after several months with an unchanged treatment, as in our two patients. NMS risk factors include high dose of NL, type of 
NL (intramuscular NL, long acting NL, older NL like haloperidol), male gender, previous history of NMS, organic brain syndrome, dehydration, surrounding heat environment, poor general status and physical exhaustion. 2,5,6 Thus, second-generation antipsychotics (SGA) such as clozapine and loxapine were initially described to be less at risk of NMS because of their pharmacodynamic profile. ${ }^{7}$ However, as in our two cases, NMS induced by SGA, at high but also low dosages, have been reported notably with clozapine ${ }^{7}$ and in a very few case with loxapine. $^{8,9}$ Moreover, other drugs with dopamine-blocking properties have been associated with neuroleptic malignant-like syndrome, such as metoclopramide, tricyclic antidrepressants or selective serotonin reuptake inhibitors. ${ }^{10,11}$ In both cases, the best possible medication history performed by the clinical pharmacist did not reveal this type of treatment. The diagnosis of NMS is unclear and very uncertain. ${ }^{2,11} \mathrm{NMS}$ is an adverse drug reaction that is uncommon, challenging to diagnose and therefore is based on clinical and biological criteria, ${ }^{12}$ and often becomes a diagnosis of exclusion. ${ }^{13,14}$ According to studies, major criteria were hyperthermia, rigidity and/ or extrapyramidal symptoms, and minor criteria were altered consciousness, tachycardia, hypertension, tachypnoea, diaphoresis and leukocytosis. ${ }^{15,16}$ For some studies, elevated CPK was a major ${ }^{15}$ or a minor $^{16}$ criteria for NMS diagnosis. Furthermore, the level of CPK in the NMS diagnosis is not clearly established ${ }^{16-18}$ and differs between studies. ${ }^{15,19}$ A large number of cases published did not mention the criteria used to diagnose NMS. ${ }^{13}$ Our two cases presented two major (hyperthermia and rigidity) and three minor (altered consciousness, hypertension and tachycardia) criteria of NMS. In addition, our two cases had increased CK and myoglobin levels. Moreover, these results and the absence of a differential diagnosis allowed us to establish the diagnosis of NMS. In addition, we observed that patient B, who presented with more severe criteria for NMS compared with patient A, also showed a greater clinical severity resulting in the death of the patient. One hypothesis may be that patient A was at the beginning of the NMS and presented less risk factors. However, NMS has a low incidence $(0.02 \%-2.4 \%$ of the patients treated by antipsychotics) but may have a fatal outcome (10\%-50\%). ${ }^{5}$ The health authorities have established a list of dangerous drugs during heatwaves, which can alter body adjustment to hot temperatures. ${ }^{20,21}$ Different drugs are involved, such as antipsychotics which inhibit sweating by anticholinergic activity and cause hyperthermia and furosemide which produces dehydration. NMS affects different areas of the brain: basal ganglia, limbic system and hypothalamus, and causes damage to thermoregulation by dopaminergic activity. ${ }^{22}$ The toxic effect on skeletal muscle is probably caused by abnormal calcium availability in muscle cells and generates muscle rigidity with possible rhabdomyolysis and hyperthermia. ${ }^{4}$

According to various studies, there is a link between heatwaves and the occurrence of NMS of malignant hyperthermia $(\mathrm{MH}) \cdot{ }^{23,24}$. Due to heat stroke, $\mathrm{MH}$ occurs spontaneously in vulnerable or sensitive patients (obese, elderly patient, psychiatric disease, etc.) without excessive agitation or exercise. A study concluded that antipsychotic medications are a risk factor of heat-related hospitalization for hyperthermia during heatwave. ${ }^{25}$
During July 2015, in the Herault region (South of France), recordbreaking temperatures were registered with high peak temperatures at $36.2^{\circ} \mathrm{C} / 96.8^{\circ} \mathrm{F}$ and $34.3^{\circ} \mathrm{C} / 93.2^{\circ} \mathrm{F}$ on the days of hospitalization of patient $A$ and patient $B$ respectively. These cases of NMS occurred in patients suffering from severe dehydration associated with risk factors during a heatwave.

\section{4 | CONCLUSION}

In the ED, clinical pharmacists have an important role. They can implement activities such as medication history, medication reconciliation or research of iatrogenic events, facilitating rapid and appropriate medical care and raising awareness of medical teams about iatrogenic events. $^{13}$

To conclude, medical and pharmaceutical teams must keep in mind that NMS is a rare pathological state but a potentially fatal adverse effect of NL drugs. It is not easily distinguishable from malignant hyperthermia during high heat. At-risk subjects must be identified, and their treatment must be evaluated and monitored to maintain a benefit-risk balance. Symptoms suggesting NMS must be rapidly identified, in particular during heatwave periods.

\section{ACKNOWLEDGEMENTS}

We thank Valérie Macioce for revising the manuscript.

\section{REFERENCES}

1. Katus LE, Frucht SJ. Management of serotonin syndrome and neuroleptic malignant syndrome. Curr Treat Options Neurol. 2016;18:39. Epub 2016/07/30.

2. Tse L, Barr AM, Scarapicchia V, Vila-Rodriguez F. Neuroleptic malignant syndrome: a review from a clinically oriented perspective. Curr Neuropharmacol. 2015;13:395-406.

3. Perry PJ, Wilborn CA. Serotonin syndrome vs neuroleptic malignant syndrome: a contrast of causes, diagnoses, and management. Ann Clin Psychiatry. 2012;24:155-162.

4. Adnet P, Lestavel P, Krivosic-Horber R. Neuroleptic malignant syndrome. Br J Anaesth. 2000;85:129-135.

5. Tural U, Onder E. Clinical and pharmacologic risk factors for neuroleptic malignant syndrome and their association with death. Psychiatry Clin Neurosci. 2010;64:79-87.

6. Bristow MF, Kohen D. Neuroleptic malignant syndrome. Br J Hosp Med. 1996;55:517-520.

7. Belvederi Murri M, Guaglianone A, Bugliani M, et al. Secondgeneration antipsychotics and neuroleptic malignant syndrome: systematic review and case report analysis. Drugs R\&D. 2015;15:45-62.

8. Chandran GJ, Mikler JR, Keegan DL. Neuroleptic malignant syndrome: case report and discussion. CMAJ. 2003;169:439-442.

9. Paul M, Michael SG, John S, Lenox RJ. An atypical presentation of neuroleptic malignant syndrome: diagnostic dilemma in a critical care setting. Respir Care. 2012;57:315-317.

10. Margetic B, Aukst-Margetic B. Neuroleptic malignant syndrome and its controversies. Pharmacoepidemiol Drug Saf. 2010;19:429-435.

11. Oruch R, Pryme IF, Engelsen BA, Lund A. Neuroleptic malignant syndrome: an easily overlooked neurologic emergency. Neuropsychiatr Dis Treat. 2017;13:161-175. 
12. Gurrera RJ, Caroff SN, Cohen A, et al. An international consensus study of neuroleptic malignant syndrome diagnostic criteria using the Delphi method. J Clin Psychiatry. 2011;72:1222-1228.

13. Pileggi DJ, Cook AM. Neuroleptic malignant syndrome review: focus on treatment and rechallenge. Ann Pharmacother. 2016;50:973-981. Epub 2016/07/18.

14. Khouri C, Planes S, Logerot S, Villier C, Mallaret M. Syndrome malin des neuroleptiques et difficultes diagnostiques: a propos d'un cas [Case report: Neuroleptic malignant syndrome and diagnostic difficulties]. L'Encephale. 2016;42:277-280.

15. Levenson JL. Neuroleptic malignant syndrome. Am J Psychiatry. $1985 ; 142: 1137-1145$.

16. Lazarus A. Neuroleptic malignant syndrome. Hosp Community Psychiatry. 1989;40:1229-1230.

17. Addonizio G, Susman VL, Roth SD. Neuroleptic malignant syndrome: review and analysis of 115 cases. Biol Psychiatry. 1987;22:1004-1020.

18. Adityanjee A, Aderibigbe YA, Mathews T. Epidemiology of neuroleptic malignant syndrome. Clin Neuropharmacol. 1999;22:151-158.

19. Pope HG Jr, Keck PE Jr, McElroy SL. Frequency and presentation of neuroleptic malignant syndrome in a large psychiatric hospital. Am J Psychiatry. 1986;143:1227-1233.

20. Nordon C, Martin-Latry K, de Roquefeuil L, et al. Risk of death related to psychotropic drug use in older people during the European
2003 heatwave: a population-based case-control study. Am J Geriatr Psychiatry. 2009;17:1059-1067.

21. Martinez M, Devenport L, Saussy J, Martinez J. Drug-associated heat stroke. South Med J. 2002;95:799-802.

22. Waldorf S. AANA journal course. Update for nurse anesthetists. Neuroleptic malignant syndrome. AANA J. 2003;71:389-394.

23. Hajat S, O'Connor M, Kosatsky T. Health effects of hot weather: from awareness of risk factors to effective health protection. Lancet. 2010;375:856-863.

24. Suh $\mathrm{H}$, Bronson B, Martin R. Neuroleptic malignant syndrome and lowdose olanzapine. Am J Psychiatry. 2003;160:796. Epub 2003/04/02.

25. Martin-Latry K, Goumy MP, Latry P, et al. Psychotropic drugs use and risk of heat-related hospitalisation. Eur Psychiatry. 2007;22:335-338. 